\title{
Effect of socioeconomic deprivation and the appointment of Welfare Attorneys
}

\author{
M G Booth*, E O’ Neil ${ }^{\dagger}$, C Haddow $\ddagger$ B Cook ${ }^{\S}$ and J Kinsella*
}

*Glasgow Royal Infirmary, Glasgow, UK; ${ }^{\dagger}$ Office of the Public Guardian, Falkirk, Scotland, UK; ${ }^{*}$ Information \& Statistics Division, South Gyle Crescent, Edinburgh, Scotland, UK; ${ }^{\S}$ Chair Scottish Intensive Care Society Audit Group, Edinburgh Royal Infirmary, Edinburgh, Scotland, UK

E-mail: malcolm.booth@nhs.net

\begin{abstract}
Most patients in intensive care unit (ICU) lack decision-making ability. The Adults with Incapacity (Scotland) Act 2000 allows someone to appoint a Welfare Attorney (WA) to act on their behalf should they lose capacity. Scotland has areas of major socioeconomic deprivation associated with lower life-expectancy and with a lack of knowledge about and consequently difficulty accessing services. The effect of socioeconomic deprivation on WA registration was investigated. A complete list of registered WAs was categorized by deprivation. The Public Guardian, Scotland indicated whether patients admitted to ICU at Glasgow Royal (April 2006-May 2009) had a WA registered. All Scottish ICU admissions (2004-2008) were categorized by deprivation. Twelve of 1152 ICU patients at Glasgow Royal had a WA. Of 165,997 WAs registered, 5984 were in the most deprived and 27,970 in the most affluent areas. Overall, $3.9 \%$ of the Scottish population had a WA $(1.4 \%$ in the most, $6.5 \%$ in the least deprived population decile). In conclusion, the uptake of WAs was low, especially in deprived areas. The reasons could include a lack of knowledge, not anticipating the need for a WA or not being confident in the process. Any educational package needs to target the most socioeconomically disadvantaged.
\end{abstract}

Keywords: critical care, incapacity, socioeconomic deprivation, consent

\section{Introduction}

The majority of patients in intensive care units (ICUs) lack the capacity to participate in decision-making. This can be due to underlying illness or treatment, or both. As a result of a critically ill patient's diminished capacity, the relatives are often involved in the decision-making process.

Similar problems with decision-making can occur in other health-care areas, such as care of the elderly, where patients may lack or have fluctuating mental capacity.

In many countries the relatives' involvement in the decision-making process has been formalized, with legislation being passed to enable the relatives to act on behalf of the incapacitated person. In Scotland, the Adults with Incapacity (Scotland) Act $2000^{1}$ sets out the criteria to determine incapacity and who may act on the incapacitated person's behalf. The Act also allows an adult (aged 16 or over in Scotland) to appoint a nominated person to act in their place in the event that they should lose capacity. The nominated person (designated as the Welfare Attorney [WA]) is required to set aside their own values and make decisions as the appointing person would have. This assumes a significant level of communication between the two parties at the time the person agrees to be appointed as a WA.
The Mental Capacity Act 2005 fulfils a similar role in England and Wales. ${ }^{2}$

As health-care interventions become more complex and invasive, the proportion of the increasingly elderly population who are rendered incapacitated from a decision-making perspective is likely to increase substantially. At the same time it is becoming more evident that patients wish to exert their right to selfdetermination. This desire will extend into the periods when they may temporarily lose the ability to communicate their wishes. ${ }^{3}$

Every WA appointed is registered with the Office of the Public Guardian, Scotland. Since the implementation of the Act in 2002, approximately 20-30,000 WAs have been registered each year (Office of the Public Guardian, Scotland, personal communication). Central registration of the WAs allows anyone claiming to be acting as a WA to have this confirmed.

Scotland has areas of major socioeconomic deprivation. Deprivation is associated with poorer health and life-expectancy. ${ }^{4}$ This is evident in Scotland, with a lower life-expectancy and higher rates of heart disease, cancer, alcohol addiction and suicide. ${ }^{5}$ Even within Scotland there is great variation in socioeconomic deprivation and its effect on health; for example, there is a 
difference in life-expectancy of 28 years between the most affluent and most deprived suburbs of Glasgow. ${ }^{6,7}$

Glasgow Royal Infirmary is a university teaching hospital that serves a socioeconomically deprived inner city area. The ICU at Glasgow Royal Infirmary is a ninebedded unit which receives tertiary referrals including acute severe pancreatitis, burns and major trauma. Historically, $66 \%$ of admissions to the ICU at Glasgow Royal come from areas considered to be among the most deprived in Scotland (Scottish Intensive Care Society Audit Group, personal communication).

Social deprivation in Scotland is measured by the Scottish Index of Multiple Deprivation (SIMD). ${ }^{8}$ The latest report, SIMD 2009, identifies small area concentrations of deprivation (data zones) across Scotland. The population in each data zone is similar in number but each zone is assessed in seven domains namely: income, employment, health, education, skills and training, housing, and geographic access and crime. There are 6505 data zones ranked from the most deprived (ranked 1) to the most affluent (ranked 6505). A person's data zone can be identified from their postcode sector. For example, for the postcode G4 OSF the postcode sector would be G4 0 .

Another aspect of social deprivation is an associated lack of knowledge about, and therefore difficulty accessing, services. Consequently, although services may be available they are not used. At the time of the implementation of the AWI Act there was little knowledge of the changes among relatives of ICU patients. ${ }^{9}$ Since the implementation of the AWI Act in 2001, none of the ICU staff were aware of anyone ever claiming to be acting as a patient's WA. We therefore performed an investigation to establish whether the uptake of Welfare Attorney registration differed across socioeconomic groups in Scotland and whether social deprivation appeared to have any influence on this process.

\section{Methods}

A complete list of the number of WAs registered in each postcode sector as of 30 September 2010, was prepared by the Office of the Public Guardian, Scotland. The postcodes were allocated to their SIMD data zone using the interactive mapping function on the SIMD website. The data zones were ranked in deciles, with decile 1 being the most deprived 10\% of the 6505 data zones and decile 10 being the $10 \%$ most affluent. Population data, namely the total population of Scotland and the number of adults, were retrieved from the General Registrar Office for Scotland website. ${ }^{10}$

Following discussion with the Caldecott Guardian and the Data Protection Officer and their approval, a list of patients admitted to ICU at Glasgow Royal Infirmary between April 2006 and May 2009 was hand delivered to the Office of the Public Guardian, Scotland. A number of safeguards were used to ensure that sensitive patient data were kept secure. This included the hand delivery of patient data. The Public Guardian indicated whether the patients had a WA registered at the time of ICU admission or had registered one since ICU discharge.
The Scottish Intensive Care Society Audit Group and the Information Statistics Division of NHS Scotland prepared a data-set of the number of ICU admissions across Scotland for the period 2004-2008 inclusive. All admissions were categorized by their SIMD grouping.

\section{Results}

There were 1152 patients admitted to the ICU at Glasgow Royal Infirmary between 1 April 2006 and 30 May 2009. Of these, 12 had a WA registered prior to ICU admission. Eleven had registered a WA since their discharge from hospital.

The total number of WAs registered in Scotland at 30 September 2010 was 165,997. There were 5984 WAs registered to the data zones in decile 1 , the most deprived, and 27,970 in decile 10, the most affluent (see Table 1). There was a gradual increase in the number of WAs registered in each progressively more affluent SIMD decile.

The total Scottish population was 5,194,000 and 4,281,660 of these were adults.

Each data zone should have similar number of occupants. Consequently, SIMD decile contains 10\% of the population. Overall, 3.9\% of the Scottish population had a WA registered. This ranged from $1.4 \%$ in decile 1 to $6.5 \%$ decile 10 .

People from more deprived parts of the community are over-represented in ICU. Over the period 2004-2008, $39 \%$ of ICU patients in Scotland came from the three most deprived deciles. Conversely, the three most affluent deciles only contributed $19 \%$ of ICU patients (SICSAG, personal communication).

\section{Discussion}

These results demonstrate that overall the uptake of WAs among the adult population of Scotland has been low.

Table 1 Number of Welfare Attorneys registered to each decile of the SIMD 2009 population (data at 30 September 2010)

\begin{tabular}{lcl}
\hline SIMD decile & $\begin{array}{l}\text { Number of Welfare } \\
\text { Attorneys registered }\end{array}$ & $\begin{array}{l}\text { \% Adult population per } \\
\text { decile with WA } \\
(4,281,660)\end{array}$ \\
\hline 1 & 5984 & 1.4 \\
2 & 9122 & 2.1 \\
3 & 11,408 & 2.7 \\
4 & 12,972 & 3.0 \\
5 & 15,032 & 3.5 \\
6 & 17,086 & 4 \\
7 & 20,240 & 4.7 \\
8 & 22,217 & 5.2 \\
9 & 23,966 & 5.6 \\
10 & 27,970 & 6.5 \\
Total & 165,997 & 3.9 \\
Assumes & & \\
population of & & \\
$4,281,660$ & &
\end{tabular}

SIMD, Scottish Index of Multiple Deprivation 
The reasons for this poor uptake are currently unknown. It is not known as to whether this is due to a lack of knowledge. The role of the WA is wider than the previous powers allowed to people appointed with Power of Attorney, as this did not cover decisions about health care. An alternative explanation could be that patients had not anticipated becoming ill and therefore although they knew about the Welfare Attorney process, had felt that was not relevant to them. It may have been that although the process was known to the potential patient, that they did not wish to discuss this matter with their relatives or that they did not feel that they could rely on a prospective WA to represent their views. An understanding of these potential obstacles will be the subject of a further study.

We were able to gain a clear impression that those least likely to require a WA, i.e. the population from the most affluent groups, were the most likely to actually appoint one. Again, this feature may reflect a better knowledge and understanding of the process. Alternatively, the motivation for having a WA may not have been from the health care decisions but the ability to manage someone's finances in the event of incapacity. Nonetheless, the uptake even among the most affluent members of the population still appears to be surprisingly poor.

Any educational package or publicity regarding this process must reach the groups most likely to require a WA. Therefore, the most socioeconomically deprived would need to be targeted in any such campaign.

For clinicians managing an incapacitated patient it is highly desirable to have knowledge of the patient's attitudes with regard to life-sustaining treatment, the burdens of such treatment and the levels of risk regarding death or serious disability that they are prepared to accept. The default position for relatives who have not discussed such matters previously, and indeed critical care clinicians, is to assume that the person would be prepared to accept most, if not all, of the support that critical care can provide. This is in contrast to the wishes that are often expressed by patients who frequently have realistic expectations regarding the burden of care that they are prepared to accept in the light of a likelihood of a poor outcome. As a result the impression is often gained that patients receive far more treatment than they would have ordinarily wished for, had they been able to express their views.

We noted that a small number of patients had actually appointed a WA after being critically ill. We can only speculate on their motivation due to the confidentiality of this survey, but it appears to be likely that their experience led to a desire to be able to influence future decision-making.

Of the 12 patients who had appointed a WA prior to their admission to ICU, we realized that none of the WAs had made their position known to the medical or nursing staff. There are many possible explanations, such as the appointed WA had died, or was no longer in contact with the patient. It does raise the possibility that although some WAs were visiting patients, they chose not identify themselves as such. While we would like to think that the explanation was that they were perfectly happy with the treatment and care that was been provided, the possibility that other explanations, such as an unwillingness to admit that their relative would have wanted to have their treatment limited, may be involved.

This survey shows that the Welfare Attorney process is only being taken up be a small proportion of the population and that those most likely to require critical care are the most deprived, and their rate of appointment is very low. Furthermore, even those patients who have appointed a WA do not benefit from this if the ICU staff are not informed.

As a result of this survey, we propose to routinely enquire whether any of the relatives have been appointed as a WA. In addition, we now provide literature to the relatives on the WA process, with the intention that over time they may consider utilizing this service themselves. We will also investigate further the reasons as to why patients either do, or do not, make use of this service so that we can establish whether it would be appropriate to have a much wider educational and recruitment campaign.

\section{Declaration}

None of the authors have any financial or commercial interest to declare.

\section{References}

1 Adults with Incapacity (Scotland) Act 2000. See www.legislation.gov. uk/asp/2000/4/contents (last checked 24 October 2011)

2 Mental Capacity Act 2005. See www.legislation.gov.uk/ukpga/2005/ 9/contents (last checked 3 March 2011)

3 Kinsella J, Booth MG. Ethical framework for end of life decisions in intensive care in the UK. J Natl Inst Public Health 2007;56:387-92

4 Clark D, McKeon A, Sutton M, Wood R. Healthy Life Expectancy in Scotland. Information Services Division of NHS Scotland 2004. See www.isdscotland.org/isd/files/HLE_report_2004.pdf (last checked 3 March 2011)

5 Shaw M, Thomas B, Smith GD, Dorling D. The Grim Reaper's Road Map. An Atlas of Mortality in Britain. Bristol: The Policy Press, 2008

6 de Caestecker L, Lachlan M. A call to debate: a call to action. A report on the health of the population of NHS Greater Glasgow and Clyde 2007-2009. NHS Greater Glasgow and Clyde 2010

7 World Health Organisation Commission on Social Determinants of Health. Closing the gap in a generation. Health Equity through action on the social determinants of health. The Final Report of the WHO Commission on the Social Determinants of Health. World Health Organisation, August 2008. See www.who.int/ social_determinants/thecommission/finalreport/en/index.html (last checked 3 March 2011)

8 Scottish Index of Multiple Deprivation. The Scottish Government. See www.scotland.gov.uk/Topics/Statistics/SIMD/SIMDInteractive (last checked 3 March 2011)

9 Booth MG, Doherty P, Fairgrieve R, Kinsella J. Relatives knowledge of decision making in intensive care. J Med Ethics 2004;30:459-62

10 General Registrar Office for Scotland. See http://www.gro-scotland. gov.uk/statistics/theme/population/estimates/mid-year/2009/ index.html (last checked 3 March 2011) 